\title{
De introductie van competentiegerichte specialistenopleidingen in Nederland*
}

F. Scheele, P. Teunissen, S. van Luijk, E. Heineman, L. Fluit, H. Mulder, A. Meininger, M. WijnenMeijer, G. Glas, H. Sluiter, T. Hummel

\section{Samenvatting}

Bestuurlijke organen op het gebied van de gezondheidszorg hebben op allerlei plaatsen in de wereld het initiatief genomen tot modernisering van de specialistenopleidingen. Enkele jaren geleden heeft ook Nederland wetgeving gekregen die een verandering in de curricula van medische specialistenopleidingen voorschrijft.

In dit artikel beschrijft de Begeleidingsgroep Beschrijvingen Opleidingsplannen Vervolgopleidingen (BBOV) de ervaringen met het ontwerpen van curricula voor specialistenopleidingen die gebruik maken van de Canadian Medical Education Directions for Specialists (CanMEDS).

De meeste Nederlandse wetenschappelijke verenigingen baseren hun curriculumontwerp op een model met drie stappen. Eerst verdelen zij de inhoud van hun specialisme in logische eenheden, zogenaamde thema's. Als tweede stap kiezen zij binnen elk thema een beperkt aantal taken waarop de arts in opleiding tot specialist (aios) naast instructie en begeleiding getoetst dient te worden. Als laatste stap bepalen ze voor iedere gekozen taak een toetsmethode, waarbij steeds enkele CanMEDS competenties expliciet aandacht krijgen. Dit leidt tot een driestaps opleidingscyclus. Op basis van hun praktijkvoering en toetsing verzamelen de aios bewijs voor hun ontwikkeling en voegen dit in hun portfolio samen (1). Dit bewijs stimuleert de aios en de opleider om regelmatig te reflecteren op de globale ontwikkeling van de aios in de verschillende CanMEDS competenties en in de specifieke taken (2). Een persoonlijk ontwikkelplan structureert vervolgens toekomstige leerdoelen en -strategieën (3).

De ervaringen in Nederland sluiten aan bij internationale ontwikkelingen in de specialistenopleidingen en bij bestaande literatuur over leren op de werkplek. (Scheele F, Teunissen P, Luijk $S$ van, Heineman E, Fluit L, Mulder H, Meininger A, Wijnen-Meijer M, Glas G, Sluiter H, Hummel T. De introductie van competentiegerichte specialistenopleidingen in Nederland. Tijdschrift voor Medisch Onderwijs 2008;27(5):221-229.)

\section{Inleiding}

In het verleden maakte de hoge status van dokters het mogelijk dat het opleiden van specialisten vrijwel zonder maatschappelijke controle verliep. ${ }^{1}$ Tegenwoordig eist de maatschappij meer transparantie betreffende inhoud en kwaliteit van de specialistenopleidingen. ${ }^{2}$ Over de gehele we- reld is gekozen voor competentiegericht opleiden van medisch specialisten. ${ }^{3}$ Net als in Denemarken en Canada is in $\mathrm{Ne}$ derland gekozen voor de zeven rollen - in Nederland vertaald als 'algemene competenties' - van de Canadian Medical Education Directions for Specialists (CanMEDS). In het hart van dit raamwerk ligt

\footnotetext{
* Dit artikel verscheen eerder onder de oorspronkelijke titel: Scheele F, Teunissen P, Van Luijk S, Heineman E, Fluit L, Mulder H, Meininger A, Wijnen-Meijer M, Glas G, Sluiter H, Hummel T. Introducing competency-based postgraduate medical education in the Netherlands. Med Teach 2008;30(3);248-53.
} 
de algemene competentie 'medisch expert'. Om een goede medische professional te zijn moet deze algemene competentie worden aangevuld met de zes andere algemene competenties: communicatie, samenwerking, organisatie, maatschappelijk handelen, kennis \& wetenschap en tenslotte professionaliteit. ${ }^{4}$

\section{De ontwikkeling in Nederland}

Sinds 2006 wordt de verandering naar competentiegerichte specialistenopleidingen in Nederland ondersteund door overheidsorganen die de Begeleidingsgroep Beschrijvingen Opleidingsplannen Vervolgopleidingen (BBOV) hebben geïnstalleerd. Deze tijdelijke begeleidingsgroep is recent overgegaan in de werkgroep Medische Vervolgopleidingen van de NVMO. De BBOV bestond uit vijf onderwijskundigen, vier specialistenopleiders en één arts in opleiding tot specialist (aios). Deze groep begeleidde de wetenschappelijke verenigingen van alle 27 specialismen bij het ontwerpen van een op maat gesneden curriculum met inachtneming van de wettelijk vastgestelde kaders.

Door de BBOV werden de door de diverse wetenschappelijke verenigingen ingediende voorstellen voor competentiegericht opleiden intern besproken en met de verenigingen bediscussieerd. Op basis van literatuurstudie en ervaringen met de wetenschappelijke verenigingen kon de BBOV best practices en verhelderende modellen verspreiden. Dit proces heeft geleid tot consensus over de wijze waarop in grote lijn competentiegericht opleiden en toetsen voor alle medische specialismen plaats zou moeten vinden. Medio 2008 hadden 19 specialismen hun curriculum ingediend bij het Centraal College Medische Specialismen (CCMS); de overblijvende acht worden in de tweede helft van 2008 verwacht. In dit artikel beschrijven we de ervaringen bij het ontwerpen van competentiegerichte opleidingen en toetsing in Nederland. We beginnen met de drie stappen die gebruikt werden voor de vaststelling van inhoud en toetsing binnen het curriculum. Vervolgens zullen wij een daaruit volgende cyclus van drie stappen voor competentiegerichte opleiding en toetsing in de klinische praktijk presenteren.

\section{Uitdagingen op twee terreinen}

Bij het ontwerpen van een competentiegericht curriculum voor specialistenopleidingen komt men meerdere problemen tegen. In nationale en internationale discussies bleek dat de eerste uitdaging ligt in het ontwikkelen van een curriculum dat past bij de wettelijke voorschriften. De tweede uitdaging is het ontwikkelen van een curriculum dat ook daadwerkelijk praktisch uitvoerbaar is.

\section{Curriculumontwerp binnen de \\ Nederlandse wetgeving}

De eerste uitdaging is het ontwerpen van curricula die voldoen aan de wettelijke vereisten en tegelijkertijd door de betreffende specialismen toch als voldoende 'eigen' worden beschouwd. Elk van de 27 medische specialismen moet haar eigen competentiegerichte curriculum ontwerpen. Er is wel een behoorlijke ruimte voor verschillen tussen de curricula maar er zijn ook eisen waaraan alle curriculumbouwers dienen te voldoen (box 1). Het ontwerp moet modulair zijn, het toetsprogramma moet voornamelijk formatief zijn en gebruik maken van een portfolio. Al bij de start van het hele project was duidelijk dat de curriculumverandering gepaard moest gaan met training van opleiders en met goede kwaliteitszorg. In vrijwel iedere wetenschappelijke vereniging kwamen vragen boven als: 'Hoe vertaal je algemene competenties in de dagelijkse opleidingspraktijk?' 'Hoe stellen we goed functioneren vast in een competentiege- 
richt curriculum?' 'En hoe beschermen we het integrale karakter van het medische werk in plaats van op te leiden in afzonderlijke algemene competenties?'

Opleiding aangepast aan klinische praktijk De volgende uitdaging bevindt zich op het niveau van de werkplek. Specialistenopleidingen hebben zich altijd op de werkplek afgespeeld en dat zal zo blijven ondanks de huidige veranderingen. ${ }^{5}$ Aios leren door werkervaring in de dagelijkse praktijk. ${ }^{6}$ Dit leren op de werkplek kan niet tot in detail gepland worden op basis van didactische inzichten, maar hangt af van de presentatie van de patiënten met hun verschillende aandoeningen. De supervisie van aios wordt minder wanneer zij meer ervaring krijgen. ${ }^{7}$ Die supervisie neigt zich te concentreren op wat de opleiders het beste kunnen: op de algemene competentie 'medisch expert'. ${ }^{8}$ In deze context wordt het wel duidelijk waarom specialisten en aios vaak huiverig zijn bij het introduceren van een competentiegerichte opleiding en toetsing. Veel voorkomende vragen zijn: 'Kost dit nieuwe opleidingsprogramma niet te veel waardevolle klinische opleidingstijd?' 'Leidt dit niet tot onnodige bureaucratie?' 'Zullen patiënten werkelijk beter worden van deze exercitie?'

Box 1. Kaders voor gemoderniseerde medische vervolgopleidingen.

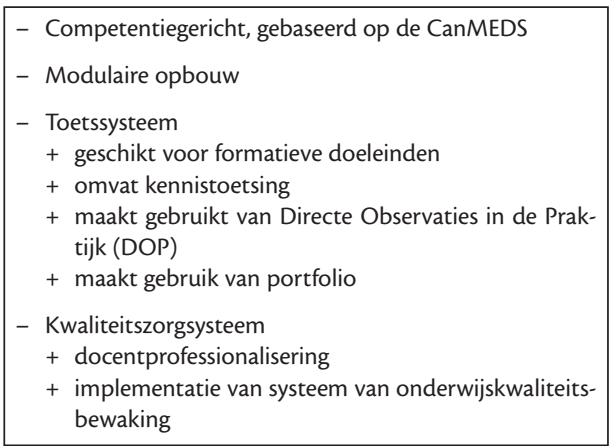

\section{De drie stappen in het curriculumontwerp}

De ervaring heeft geleerd dat de volgende drie stappen veel houvast bieden bij het ontwerpen van een competentiegericht curriculum.

\section{Stap 1: geef structuur aan de inhoud}

De beheersing van de praktijk van een medisch specialisme is het gevolg van integratie van kennis, veel vaardigheden en een goede attitude. Vragen als 'wat moet er nou het eerst geleerd worden?' en 'op welke onderwerpen moet wanneer gefocust worden?' waren de reden om de inhoud van de specialismen te structureren. De eerste stap is de onderverdeling van de hele inhoud van een medisch specialisme in logische eenheden (figuur 1). De BBOV adviseerde de beroepsgroepen te zoeken naar consensus over een expliciete onderverdeling van het vak in eenheden (de zogenaamde thema's). Verschillende specialismen kozen verschillende indelingsprincipes om tot thema's te komen, bijvoorbeeld anatomische regio's (Orthopedie), context (Psychiatrie), symptomen (Heelkunde) of een mix van context en symptomen (Verloskunde \& Gynaecologie). Die thema's maken het mogelijk het curriculum te structureren. De meeste curricula maken al gebruik van onderverdeling in stages, vaak meer dan in één ziekenhuis. Dit stagesysteem was echter onvoldoende om de gehele inhoud van een specialisme onder te verdelen omdat stages vaak meer gefocust zijn op de bedrijfsvoering en de patiëntenzorg dan op een efficiënt opleidingsprogramma. Bovendien verschilt de volgorde van stages nogal tussen verschillende opleidingsziekenhuizen. In de nieuwe curricula zullen sommige thema's volledig aan bod komen binnen één stage terwijl andere thema's aandacht nodig hebben binnen meerdere stages. 
Stap 2: kies de meest leerzame activiteiten De tweede stap in het curriculumontwerp was binnen ieder thema vast te stellen welke aspecten van de zorg zich goed lenen voor instructie, begeleiding en toetsing. Natuurlijk bevat ieder thema een grote hoeveelheid zorgtaken en de aios moeten die allemaal tot op zeker niveau leren. Wij accepteren dat aios met name het minder risicovolle klinische werk wel leren uit de dagelijkse routine. ${ }^{9} \mathrm{Om}$ te besluiten welke zorgactiviteiten meer expliciete aandacht in de opleiding verdienen hebben wij het concept van de 'Entrustable Professional Activities' (EPA) van Ten Cate gebruikt. ${ }^{10}$ Wij ontwikkelden drie criteria om EPA's te kiezen:

- Een taak is van het hoogste belang voor de dagelijkse praktijk (core business).

- Een taak heeft een hoog risico; er is een grote kans op fouten.

- Een taak is zeer geschikt als voorbeeld van specifieke (algemene) CanMEDS competenties.

Wetenschappelijke verenigingen bleken uitstekend in staat op deze manier een beperkt aantal EPA's te benoemen binnen ieder thema. Over het algemeen werd er over core business en hoge risico EPA's al snel overeenstemming bereikt. De EPA's die als voorbeeld kunnen dienen voor specifieke CanMEDS competenties gaven wat meer discussie. Voorbeelden van zulke EPA's zijn 'triage op de eerste hulp' (organisatie), 'leiderschap op de verloskamer' (samenwerking), of 'het evalueren van ongelukken op de operatiekamer' (maatschappelijk handelen). Dit zijn taken waarmee aios de algemene competenties samenwerking, organisatie, maatschappelijk handelen en professionaliteit kunnen oefenen en laten zien. De focus op andere algemene competenties dan medisch expert, kennis $\&$ wetenschap en communicatie is relatief nieuw. Het is daarom belangrijk de hoe- veelheid aandacht die aan iedere algemene competentie wordt gegeven zorgvuldig uit te balanceren. De meeste ontworpen curricula bevatten twee tot vijf EPA's per thema die speciaal gericht zijn op de ontwikkeling van de nieuwe CanMEDS competenties. Dat resulteert in 50 tot 60 van zulke EPA's gedurende de hele lengte van de specialistenopleiding. Voor al die EPA's is coaching en toetsing nodig waarmee zichtbaar gemaakt wordt welke kennis, vaardigheden en attitude bovengemiddeld belangrijk gevonden worden.

\section{Stap 3: gebruik het toetsarsenaal om}

diverse CanMEDS competenties te toetsen Als de thema's gedefinieerd zijn en de EPA's gekozen rest de laatste stap. Deze behelst het juiste gebruik van het toetsarsenaal om EPA's te beoordelen (figuur 1). Het toetsarsenaal bevat diverse methoden. ${ }^{11}$ Bij het toetsen op de werkplek kan gebruik worden gemaakt van directe observaties (de korte praktijkbeoordeling - KPB - en de Objective Structured Assessment of Technical Skills - OSATS), van beoordelingen tijdens simulatietrainingen, van de documentatie van ervaringen in een logboek en van Critically Appraised Topics of clinical problems (CAT's). 360 graden beoordelingen zijn optioneel maar worden sterk aangeraden. Bovendien raadde de BBOV verenigingen aan mondelinge of schriftelijke kennistoetsen af te nemen en vaardigheidslaboratoria in te zetten om essentiële vaardigheden in gecontroleerde omstandigheden te trainen en te toetsen.

Verschillende toetsmethoden passen bij verschillende aspecten van de opleidingspraktijk. Voor elke EPA werd een toetsmethode gekozen met focus op een beperkt aantal CanMEDS competenties. De algemene competentie 'medische expert' werd meestal gekozen en werd dan aangevuld met één of twee andere algemene competenties. De focus op enkele competenties 
per EPA zorgt voor een specifiekere feedback die daardoor meer waarde krijgt. ${ }^{12}$ Enerzijds gaat het erom dat praktijkobservaties plaatsvinden bij taken die de professie zelf met zorg uitkiest, anderzijds is het belangrijk zeker te stellen dat alle CanMEDS competenties voldoende aandacht krijgen.

\section{Competentiegerichte opleiding in de praktijk: een driestaps cyclus}

De opleidingsplannen die uit het driestaps curriculum ontwerpproces gekomen zijn leggen de basis voor een driestaps trainingscyclus.

\section{Bijhouden van een portfolio}

Tijdens een stage moet de aios focussen op het beheersen van een beperkt aantal thema's en de daarbij behorende EPA's die de vertaling van de leerdoelen zijn. Aios moeten bewijzen vergaren voor hun persoonlijke ontwikkeling en deze in hun portfolio bijeen brengen. De belangrijkste informatie voor het portfolio komt uit de toetsing in de praktijk. Die informatie moet worden aangevuld door bijvoorbeeld bewijzen van cursussen waar kennis en vaardigheden zijn bijgespijkerd. Het portfolio dient zo gestructureerd te worden dat het bruikbaar wordt voor de reflectie op de ontwikkeling als medische professional en op de bijbehorende sterkte / zwakte analyse. Samengevat gebruikt de aios het portfolio om op een gevalideerde manier antwoord te geven op de vragen 'hoe gaat het' en 'wat wordt de volgende stap'.

\section{Voortgangsgesprekken}

In de eerste jaren van de opleiding wordt op zijn minst iedere drie maanden een formeel voortgangsgesprek gehouden, gebaseerd op het portfolio. Het resultaat van een voortgangsgesprek moet een tweedimensionaal plaatje zijn. De eerste dimen-

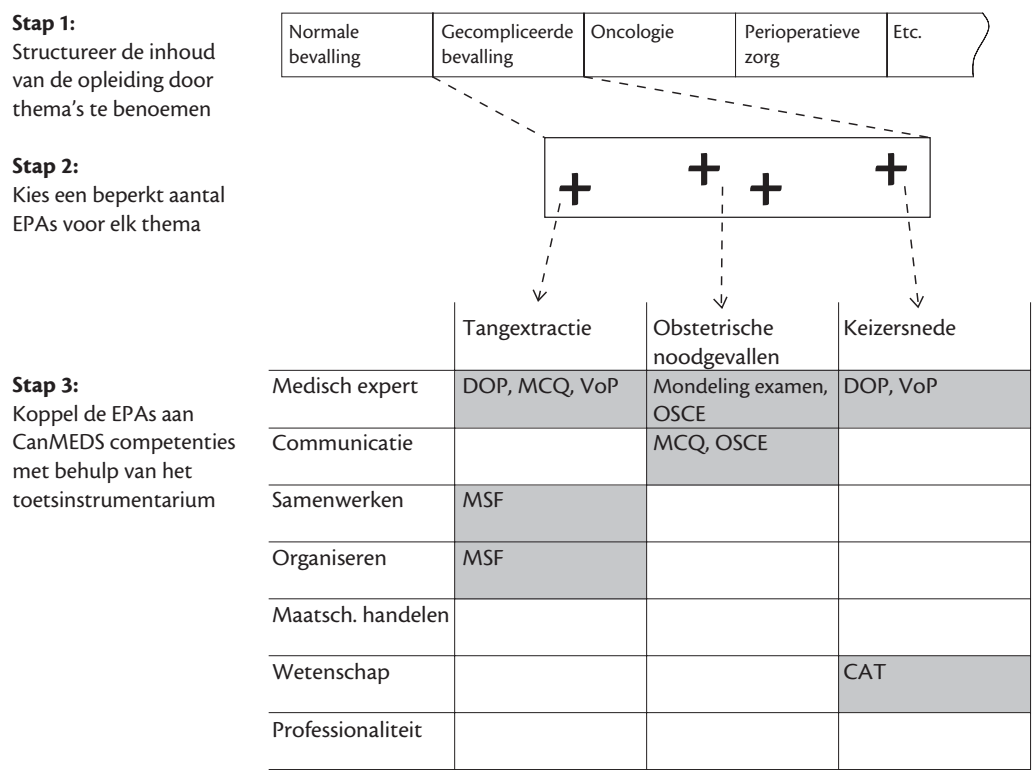

Figuur 1. Drie stappen in de bouw van curricula: een voorbeeld uit de gynaecologie.

Toetsinstrumentarium: $D O P=$ directe observaties in de praktijk, $M C Q=$ multiple choice vragen (kennistoetsing), VoP = 'volume of practice', OSCE = 'objective structured clinical examination', MSF = 'multisource' feedback, CAT = 'critically appraised topic' 
sie is een globaal maar goed onderbouwd inzicht in de ontwikkeling van de aios in de verschillende CanMEDS competenties. De tweede dimensie is een meer gedetailleerd plaatje van de bekwaamheid in specifieke EPA's dan wel in thema's. Ter voorbereiding schrijven de aios een reflectie op hun ontwikkeling in elk van de zeven CanMEDS competenties. Deze reflectie is het eerste onderwerp op de agenda voor het gesprek met de opleider. Het globale beeld van de zeven algemene competenties moet een goede ontwikkeling van al die competenties garanderen, ook in de relatief onderbelichte competenties als samenwerking en organisatie. Daarnaast gebruiken aios het portfolio om hun bekwaamheid in specifieke EPA's dan wel in gehele thema's aan te tonen. Het tweede deel van de agenda van de voortgangsbespreking gaat ook over de aanvragen voor formele bekwaamverklaringen op deelterreinen. ${ }^{13}$ Bekwaam verklaard worden voor EPA's of thema's, en daarmee tot op zekere hoogte zelfstandig zorg mogen leveren passend bij die EPA's of thema's, wordt als de ultieme beloning beschouwd voor het succesvol afronden van delen van de opleiding. Het 'jagen' op bekwaamverklaringen is een praktische manier om leerdoelen expliciet te maken en om een helder overzicht te krijgen van de voortgang van de opleiding. Bovendien kan zo'n systeem van bekwaamverklaringen voor de omgeving duidelijk maken wat een aios eigenlijk kan. Dat draagt bij aan de patiëntveiligheid en aan een voor de maatschappij inzichtelijk opleidingsprogramma.

Samengevat zijn de reflectie op de CanMEDS competenties en de aanvragen van bekwaamverklaringen het uitgangspunt voor de agenda van het voortgangsgesprek met de opleider. Uiteindelijk resulteert dit in een gedeeld beeld over de voortgang van de aios en over een passend persoonlijk ontwikkelplan.
Persoonlijk ontwikkelplan: de cirkel rond Op basis van het tweedimensionale plaatje kan de vraag 'wat wordt de volgende stap' beantwoord worden. De opleider en de aios bespreken die vraag, formuleren nieuwe leerdoelen en maken een planning: waar en wanneer kunnen de juiste ervaringen opgedaan worden en hoe kan de voortgang het best getoetst worden. De aios maakt korte notulen van dit gesprek waarin het persoonlijke ontwikkelplan voor de komende maanden beschreven staat. Bij twijfelachtig functioneren van de aios wordt een intensiever toetsprogramma afgesproken en eventueel een op maat gesneden extra begeleiding.

\section{Discussie}

Het gepresenteerde model voor curriculumontwikkeling is een poging om drie werelden bij elkaar te brengen: die van de clinici, de onderwijskundigen en de maatschappij. Na uitgebreid nationaal en internationaal discussiëren waarbij vele clinici, onderwijskundigen en beleidsmakers betrokken waren, konden we een heldere aanpak uitstippelen die paste bij de principes van competentiegericht opleiden. Om te komen tot een goede curriculumstructuur was vooral nuttig het inzicht dat de ontwikkeling van een aios het beste in twee dimensies bekeken kan worden: enerzijds de ontwikkeling in de verschillende CanMEDS competenties en anderzijds de ontwikkeling op specifieke EPA's en thema's. Voor zover wij weten is zo'n tweedimensionaal beeld nog niet eerder beschreven in de literatuur.

\section{Een internationaal perspectief}

De gemengde formatieve en summatieve toetsing op de werkplek en de gerichte keuze van taken die getoetst worden ten behoeve van het reflectieve proces op basis van een portfolio, zijn terug te vinden in het eerste jaar van de opleiding Anesthesie 
in Denemarken. ${ }^{14}$ De Britse toetsprogramma's lijken meer ontwikkeld voor summatieve doeleinden ${ }^{15}$ en zijn duidelijk intensiever dan de onze. Tot nu toe zien wij meer in formatieve toetsing in het kader van dit leren van volwassenen. Bovendien zal er bij formatieve toetsing een kleinere kans zijn op bureaucratie en leidt dit tot effectiever omgaan met tijd en middelen. Wij staan een intensiever toetsprogramma voornamelijk voor wanneer er twijfel is of een aios de doelen van het curriculum wel gaat halen. Bij het competentiegerichte opleiden, zoals door de BBOV geadviseerd, ligt de focus op leren op de werkplek; dit sluit aan bij literatuur over toetsing op de werkplek en feedback. ${ }^{16}$ Wij raden kennistesten aan maar niet op de overheersende manier waarop kennis getoetst wordt in bijvoorbeeld de Verenigde Staten. ${ }^{17}$

\section{Bevorderen van implementatie}

Bij het ontwerpen van nieuwe curricula voor specialistenopleidingen waren wij ons steeds bewust van de problemen die voortkomen uit veranderingen. ${ }^{18}$ Eén van de belangrijkste interventies om implementatieproblemen voor te zijn was het schrijverschap van de curricula binnen de diverse wetenschappelijke verenigingen te leggen. Een nadeel daarvan was dat er binnen de verschillende specialismen een behoorlijke variatie in curricula ontstond. Die verschillen en een niet uniforme terminologie kunnen lastig zijn voor organen die verantwoordelijk zijn voor bijvoorbeeld de visitatie en de kwaliteitscontroles. Daarom zijn kaders voor vorm en terminologie verder uitgewerkt. Sommige wetenschappelijke verenigingen wilden geen exemplarische EPA's aanwijzen om thema's te verbinden met CanMEDS competenties. Zij kozen voor een globalere manier van observatie van CanMEDS competenties. De BBOV vreest dat dit zou kunnen leiden tot een curriculum 'in ac- tion' dat sommige CanMEDS competenties onderbelicht laat. ${ }^{19}$

Het pilotproject 'in VIVO' dat bedoeld is om de implementatie van de nieuwe curricula voor Kindergeneeskunde en Obstetrie \& Gynaecologie te faciliteren zal spoedig meer inzicht geven in dit soort onderwerpen. Dit project moet ook meer inzicht geven in de keuze van effectieve veranderstrategieën bij de overgang naar competentiegerichte opleidingsprogramma's. Een voorbeeld van zo'n veranderstrategie is het betrekken van clinici bij het maken van opleidingsrichtlijnen. De eerste resultaten laten een positieve houding van de clinici zien ten opzichte van de nieuwe opleidingsprogramma's. ${ }^{20}$ In de praktijk zal de invoering van de driestaps trainingscyclus echter nog de nodige aandacht vragen en is vooral hierop gerichte training van opleiders en aios nodig. Om een goed praktijkvoorbeeld en rolmodel te zijn in de verschillende CanMEDS competenties moeten een aantal opleiders bijscholen in bijvoorbeeld samenwerking, organisatie en maatschappelijk handelen. We zijn nog altijd op zoek naar sterke impulsen om de medische staf te laten investeren in de nieuwe competentiegerichte opleidingen. Financiële impulsen alleen zijn waarschijnlijk onvoldoende. ${ }^{21}$

\section{Onderzoeksvragen}

De implementatie van grote onderwijskundige veranderingen bij het medische onderwijs verdient gedegen onderzoek. Deze verandering biedt ook belangrijke onderzoeksmogelijkheden in het maar beperkt onderzochte terrein van werkplek leren en toetsing. ${ }^{22}$ Voorbeelden van onderzoeksvragen zijn: 'hoe goed is de transfer van adequate communicatie of teamwork in de ene EPA naar de kwaliteit van die communicatie in een andere EPA (inhoudspecificiteit)?' En 'hoeveel EPA's moet je beoordelen om vast te kunnen 
stellen dat iemand op dat terrein medisch goed functioneert?' Andere vragen komen op rondom de introductie van de bekwaamverklaringen. We weten dat alleen een grote praktijkervaring geen garantie is voor bekwaamheid. ${ }^{23}$ Het toekennen van verantwoordelijkheid aan aios is tot nu toe voornamelijk impliciet gebeurd. ${ }^{24}$ Door zulke processen expliciet te gaan maken komt er meer inzicht in leerprocessen op de werkplek.

Wereldwijd zijn bij het opleiden van medisch specialisten veranderingen zichtbaar. $^{25}$ Ook in Nederland zijn wij, gestimuleerd door de publieke opinie en beleidsmakers, begonnen aan deze enigszins avontuurlijke opdracht. Het is volgens ons van het grootste belang om visie en ervaringen rondom deze in ons land en elders lopende projecten te delen. In zijn rol van adviseur heeft de BBOV eigenlijk een gebrek aan beschrijvingen van dergelijke projecten in de literatuur ervaren. Dit artikel was gefocust op onze visie. Wij nodigen anderen uit hun visie met ons te delen.

\section{Wat hebben we geleerd?}

- Een geschikte methode voor curriculumontwikkeling voor de specialistenopleidingen bestaat uit: eerst het structureren van de inhoud van de opleiding in thema's, vervolgens het binnen thema's leerzame en toetsbare taken definiëren en uiteindelijk uit het kiezen van de daarvoor passende toetsinstrumenten.

- Een competentiegerichte toetsstrategie die onderscheid maakt tussen de voortgaande ontwikkeling binnen CanMEDS competenties enerzijds en de toename van bekwaamheid in specifieke taken anderzijds, past bij de eisen van de kliniek.

- Een toetsprogramma dat zich baseert op exemplarische professionele activiteiten is in staat het beschreven curri- culum en het curriculum in action bij elkaar te brengen.

- De cultuur van ieder specialisme kan worden gerespecteerd bij het gebruik van ons driestaps systeem van curriculumontwikkeling doordat het variatie in vorm en focus mogelijk maakt.

\section{Literatuur}

1. Eve R,Hodgkin P. Professionalism and Medicine, in The End of the Professions? The restructuring of professional work. J. Broadbent, M. Dietrich, \& J. Roberts, eds. London: Routhledge; 1977.

2. Jones R, Higgs R, de Angelis C, Prideaux D. 2001. Changing face of medical curricula. Lancet 2001;357 (9257):699-703.

3. Pellegrini CA. Invited commentary: the ACGME Outcomes Project. American Council for Graduate Medical Education, Surgery 2002;131(2):214-215.

4. Societal Needs Working Group. Skills for the new millennium: CanMEDS 2000 project, Annals of the Royal College of Physicians and Surgeons Canada, 1996;29:206-216.

5. Poole A. The implications of Modernising Medical Careers for specialist registrars. BMJ 2003;326 (7401):194.

6. Teunissen PW, Scheele F, Scherpbier AJ, van der Vleuten CP, Boor K, van Luijk,SJ, Diemen-Steenvoorde JA. How residents learn: qualitative evidence for the pivotal role of clinical activities. Med Educ 2007b;41(8):763-770.

7. Kennedy TJ, Regehr G, Baker, GR, Lingard LA. Progressive independence in clinical training: a tradition worth defending? Acad Med 2005; 80 (10 suppl):106-111.

8. Kennedy TJT, Lingard LA. Questioning Competence: A Discourse Analysis of Attending Physicians' Use of Questions to Assess Trainee Competence. Acad Med 2007;82 (10):12-15.

9. Teunissen PW, Scheele F, Scherpbier AJ, van der Vleuten CP, Boor K, van Luijk SJ, Diemen-Steenvoorde JA. How residents learn: qualitative evidence for the pivotal role of clinical activities. Med Educ 2007b 41 (8):763-770.

10. Ten Cate O. Entrustability of professional activities and competency-based training. Med Educ 2005; 39 (12):1176-1177.

11. Norcini J, Burch V. Workplace-based assessment as an educational tool: AMEE Guide No. 31, Med Teach 2007; 29 (9):855-871.

12. Hattie J, Tumperley H. The power of feedback. Rev of Educ Res 2007;77(1):81-112.

13. Ten Cate O, Scheele F. Competency-based postgraduate training: can we bridge the gap between 
theory and clinical practice? Acad Med 2007;82 (6):542-547.

14. Ringsted C, Ostergaard D, Scherpbier A. Embracing the new paradigm of assessment in residency training: an assessment programme for first-year residency training in anaesthesiology. Med Teach 2003; 25 (1):54-62.

15. Leung WC. Competency based medical training: review. BMJ 2002; 325 (7366):693-696.

16. Govaerts MJB. In-training assessment: learning from practice. The Clinical Teacher 2006; 3:242-247.

17. Tamblyn, R, Abrahamowicz M, Dauphinee D Wenghofer E, Jacques A, Klass D, Smee S, Blackmore D, Winslade N, Girard N, Du BR, Bartman I, Buckeridge DL, Hanley, JA. Physician scores on a national clinical skills examination as predictors of complaints to medical regulatory authorities. JAMA 2007;298 (9):993-1001.

18. Weiner BJ, Helfrich CD, Hernandez SR. Organizational Learning, Innovation and Change. In: Health Care Management, Organization Design and Behaviour., 5th edn, S. M. Shortell \& A. D. Kaluzny, eds., New York: Thomson Delmar Learning, Clifton Park; 2006.

19. Remmen R. An evaluation of clinical skills training at the medical school of the University of Antwerp. University of Antwerp; 1999.

20. Wallenburg I, de Bont A, Stolk E, van Exel J, Scheele F. Similarities and differences in opinions about the first competency based postgraduate curricula in the Netherlands. AMEE abstract book 2007; Trondheim, p. 191.

21. Herzberg F, Mausner B, Schnyderman BB. The motivation to work. New York: Wiley; 1959.

22. Schuwirth LW, Van der Vleuten CP. Challenges for educationalists. BMJ 2006;333 (7567):544-546.

23. Choudhry NK, Fletcher RH, Soumerai SB. Systematic review: the relationship between clinical experience and quality of health care. Ann Intern Med 2005;142 (4):260-273.

24. Kennedy T.J, Regehr G, Baker GR, Lingard LA. Progressive independence in clinical training: a tradition worth defending? Acad.Med 2005; 80 (10 suppl):106-111.

25. Jones R, Higgs R, de Angelis C, Prideaux D. Changing face of medical curriculum. Lancet 2001; 357 (9257): 699-703.

Auteurs:

Prof. dr. F Scheele is gynaecoloog*

Drs. P. Teunissen is gynaecoloog en onderzoeker

Drs. S. van Luijk is arts en onderwijskundige*

Prof. dr. E. Heineman is ziekenhuisbestuurder en kinderchirurg*

Mw. drs. L. Fluit is arts en onderwijskundige"

Mw. dr. H. Mulder is neerlandica en onderwijskundige*

Drs. A. Meininger is onderwijskundige*

Mw. drs. M.Wijnen-Meijer is onderwijskundige*

Prof. dr. G. Glas is psychiater*

Dr. H. Sluiter is internist*

Mw. drs. T. Hummel is kinderarts in opleiding

* Allen zijn lid van de BBOV (Begeleidingsgroep Beschrijvingen Opleidingsplannen Vervolgopleidingen).

Correspondentieadres:

Fedde Scheele, Afdeling Verloskunde en Gynaecologie, Sint Lucas Andreas Ziekenhuis, J. Tooropstraat 164,1061 AE Amsterdam; e-mail:f.scheele@slaz.nl

Belangenconflict: geen gemeld

Financiële ondersteuning: geen gemeld

\section{Summary}

Medical boards around the world face the challenge of creating competency-based postgraduate training programs. Recent legislation requires that all postgraduate medical training programmes in The Netherlands be reformed.

In this article the Dutch Advisory Board for Postgraduate Curriculum Development shares some of their experiences with guiding the design of specialist training programs, based on the Canadian Medical Educational Directives for Specialists (CanMEDS).

All twenty-seven Dutch Medical Specialty Societies take three steps in designing a curriculum. First they divide the entire content of a specialty into logical units, so-called 'themes'. The second step is discussing, for each theme, for which tasks trainees have to be instructed, guided, and assessed. Finally, for each task an assessment method is chosen to focus on a limited number of CanMEDS roles.

This leads to a three step training cycle: (1) based on their in-training assessment and practices, trainees will gather evidence on their development in a portfolio; (2) this evidence stimulates the trainee and the supervisor to regularly reflect on a trainee's global development regarding the CanMEDS roles as well as on the performance in specific tasks; (3) a personal development plan structures future learning goals and strategies.

The experiences in the Netherlands are in line with international developments in postgraduate medical education and with the literature on workplace-based teaching and learning. (Scheele F, Teunissen P, Luijk S van, Heineman E, Fluit L, Mulder H, Meininger A, Wijnen-Meijer M, Glas G, Sluiter H, Hummel T. Introducing competency-based postgraduate medical education in the Netherlands. Dutch Journal of Medical Education 2008;27(5):221-229.) 